\title{
Conceptualizing the Relationship between Internal Branding and Customer Satisfaction in Hotel Industry: A Psychosocial Approach
}

Eid K. Alotaibi

College of Arts, University of Hail, Saudi Arabia

\begin{abstract}
Internal branding is a key aspect of aligning employee behavior with the values of the organization and has been linked to employee engagement and customer satisfaction. The present research seeks to develop a theoretical framework that can guide the development of an effective internal branding strategy based on the rational choice and the social exchange theory. A literature review of cross-sectional and longitudinal studies conducted in the last decade is used to accomplish this goal.

The results of this study suggest that internal branding can significantly influence employee engagement and, consequently, customer satisfaction. In consonance with the rational choice and the social exchange theory, positive brand behaviors are predicted by psychological brand ownership, an organizational culture that discourages peer aggression, and an effective use of both tangible and intangible incentives. The current research suggests several future directions that researchers can undertake to advance internal branding knowledge and its impact on customer satisfaction. Research limitations and recommendations are discussed at the end of this paper.
\end{abstract}

Keywords: Internal Branding; Customer Satisfaction; Rational Choice Theory; Social Exchange Theory; Employee Engagement.

\section{Introduction}

The emergence of corporate marketing and branding has increased awareness of the importance that employees play in corporate marketing and branding. Internal branding has emerged as a key aspect of aligning employee behaviors with the values of the organization. Being at the border between the internal and the external world of the brand, employees interacting with customers can influence how clients perceive a brand (Mosley, 2007) and, as such, influence the success of an organization to meet their customers' needs.

Given that internal branding can have a direct influence upon the success of a business, there is a growing interest in the hospitality industry to identify and influence the variables that play a role in internal branding. In this paper, it is argued that a comprehensive understanding of the relationship between internal branding and customer satisfaction requires the development of a and testing of a theoretical framework.

\section{Review of Literature}

The emergence of corporate marketing and branding has increased awareness of the importance that employees play in corporate marketing and branding. Internal branding has emerged as a key aspect of aligning employee behaviors with the values of the organization. Being at the border between the internal and the external world of the brand, employees interacting with customers can influence how clients perceive a brand (Mosley, 2007) and, as such, influence the success of an organization to meet their customers' needs.

A brand can be described as a combination of name, sign, and symbol representing a group of services and/or products (Keller, 2011). The goals of internal branding are to promote the brand from within to ensure that internal and external brand messages meet customers' expectations (Punjaisri et al., 2009). Strategies aimed at increasing internal branding seek to motivate employees to engage in behaviors that reflect the values of the brand. 
More specifically, internal brand management consists of the activities taken by an organization to ensure that employees provide the brand promises reflecting the brand values (Punjaisri\& Wilson, 2011). In many cases, such activities consist of familiarizing employees with the organization's mission and values on the assumption that employees will engage in brand behaviors if they understand the brand. What some hotel managers may not acknowledge is that having brand knowledge does not necessarily imply employees will have positive attitudes and behaviors towards the brand. To engage in positive brand behaviors, employees need to have reasons that justify an extra brand behavior (Xiong et al., 2013).

Since brand knowledge does not in itself guarantees positive brand behavior, several theoretical frameworks have been used to explain employee behaviors in relation to brand behavior. Two of the most common examples are the Rational Choice theory and the Social Exchange theory, both of which understand employee brand behavior as influenced by cognitive and motivational processes. The following section provides a summary of each theory and their relevance in the understanding of internal branding.

\section{Rational Choice Theory}

The rational choice theory assumes that from a set of actions individuals select those actions that maximize their utility based on the cost of action, the relative utility of other actions, and individual preferences (Scott, 2000). Utility maximization includes factors such as respect, power, love, prestige, and money. The rational choice theory is used to explain employee behavior in general and especially how those who perform at a higher level behave at the workplace and how they are treated by peers (Campbell et al., 2017).

It is proposed that this theoretical framework can be used to explain some of the variances in brand behavior that can be observed within organizations and between organizations. Following the suggestion of Xiong et al. (2013) and the rational choice theory, it is argued that employees will engage in positive brand behaviors when they will find reasons that justify such behaviors, including organizational and peer rewards. As discussed in the following section, employee brand behavior is not only the result of rational choices but also psychological states such as psychological ownership.

\section{Social Exchange Theory}

Social exchange theory argues that employees become committed to a brand when and if they receive an exchange of benefits, which can include knowledge, support, financial incentives, and recognition (Blau, 1964). As such, employees perceiving that the organization cares about their well-being are more likely to respond with behaviors desired by the organization.

Social exchange can be emphasized in internal branding to increase brand performance, providing employees with benefits such as recognition and award. Reciprocity is a component of social exchange and employees with a high level of internal branding may be more motivated to achieve brand performance (Terglav et al., 2016).

\section{The Relationship between Internal Branding and Customer Satisfaction}

In branding literature, the employee is considered to have a key role in providing the service as promised by the brand (Punjaisri\& Wilson, 2017). When analyzing brand behavior from the lenses of the social exchange theory, two key psychological constructs often emerge, namely brand psychological ownership and brand citizenship behavior. Brand psychological ownership refers to the subjective experience of feeling brand ownership and showing commitment towards the brand. Brand citizenship behavior, on the other hand, refers to the behaviors reflecting commitment to the brand. Even without legally owning an entity, individuals can develop a sense of ownership through their psychological experiences (Rousseau \&Shperling, 2003). Organizational citizenship behavior can be defined as a discretionary behavior that promotes the 
functioning of the organization and is not explicitly recognized by the formal reward system (Organ, 2018).

Burman and Zeplin (2005) have proposed seven dimensions of brand citizenship behavior: brand consideration, helping behaviors, brand endorsement, brand enthusiasm, brand sportsmanship, brand advancement, and self-development. Brand consideration refers to the brand-centered guidelines that employees typically follow. Helping behaviors are those directed towards external customers. Brand endorsement is the willingness to endorse and defend the brand values, including in situations that are not related to the job. Brand enthusiasm includes any extra-role behavior in which employees intentionally engage. Brand sportsmanship is a state where employees don't feel the need to complain about brand-related activities. Brand advancement includes elements such as customer feedbacks which reflect employee contributions to the brand identity. Finally, self-development is the voluntary behaviors of employees meant to improve brand-centered skills, knowledge, and abilities.

The branding literature identifies two variables that can explain employee brand behavior: brand psychological ownership and brand citizenship behavior. Employees with psychological ownership of a brand have positive attitudes toward the target (Van Dyne \& Pierce, 2004), that is, towards customer. This implies that employees with a high level of internal branding are more motivated to handle customers the best they can, i.e., a high level of internal branding tends to lead to a higher level of customer satisfaction.

Given that some of the organizational citizenship brand behaviors are directed towards customers, employees with a high level of internal branding may be more likely to engage in behaviors reflecting brand consideration, brand endorsement, brand enthusiasm, brand sportsmanship, brand advancement, and helping and self-development behaviors. These behaviors are likely to increase the quality of services and, as such, customer satisfaction.

\section{Scope of the Research and Importance of the Study}

The present study argues that understanding the relationship between internal branding and customer satisfaction, as well as the effects of the variables that mediate the relationship between the same, requires a theoretical framework that explains the psycho-social factors that produce these dynamics. Specifically, it is argued that the rational choice theory and social exchange theories can be used together to explain employees' attitudes and behaviors towards the brand that they represent.

Based on the theoretical constructs presented above, it is argued that employees may become committed to a brand when and if they receive an exchange of benefits, which can include knowledge, support, financial incentives, and recognition. As such, employees perceiving that the organization cares about their well-being are more likely to respond with behaviors desired by the organization. More so, while the relationship between an employee and a brand can be -in some cases- based on incentives when the employee joins the organization, effective organizational internal branding strategies can promote the development of brand psychological ownership of the brand, which in turn strengthens positive brand behaviors and, consequently, increase customer satisfaction.

With the help of an evidence-based theoretical framework that explains the relationship between internal branding and customer satisfaction, businesses can implement evidence-based strategies that are predicted to increase customer satisfaction.

\section{Methodology}

The search strategies consisted of using several databases to cover as many relevant publications as possible. The following databases were used: EBSCO, ProQuest, and Elsevier. The keywords 
used included: "internal branding" and "engagement" and "hospitality industry" or "internal branding" and "performance" and "hospitality industry". The document type was specified as scholarly journal published between 2010 and 2020.

Several exclusion criteria were used: studies that were not peer-reviewed, books and conference proceedings, opinion pieces, anecdotical papers, studies without an abstract, and non-English articles. Of the resulting data set, one study was longitudinal, and the remaining ones were crosssectional.

\section{Findings}

Buil, Martínez\&Matute (2016) analyzed the relationship between internal brand management, organizational identification, work engagement, and organizational citizenship behavior in the hospitality industry. Data was obtained from a sample of 323 frontline employees from the main hotel chains operating in Spain. Data was collected through telephonic questionnaires and one employee from each hotel was interviewed. Quota sampling according to the size of the chains and the presence of each chain in different parts of Spain was used to obtain a representative sample. The questionnaire consisted of several Likert scale statements assessing brand-related training activities, internal brand communication, organizational citizenship behavior, organizational identification, transformational leadership, and work engagement.

According to the authors of the research described in the previous paragraph, transformational leadership has been identified as an antecedent of job engagement and organizational identification and transformational leaders have abilities that enable them to disseminate the brand to employees. Their study found that transformational leaders increase internal branding by making employees feel more connected with the hotel when they act as role models representing the brand. Hotel frontline employees also appear to show higher levels of engagement when they are committed to their leaders. These findings suggest that organizational identification and work engagement do not have a homogenous effect on citizenship behavior, with organizational identification influencing this type of behavior but not determining extra-role behaviors towards other employees and customers.

The findings of this study suggest that brand training and communication do not have a direct influence on work engagement. From the perspective of the social exchange theory, this implies that employees are not willing to reward the hotels with work engagement because these work activities do not create a more positive work-related state of mind. On the other hand, brand training and communication does have an indirect influence via organizational identification, creating a sense of affiliation or even pride towards the organization.

Wang, Ryan, and Yang (2019b) conducted a study of an internal branding project that took place for three years using a participatory action study that was designed to encourage employees to practice several core values of the organization. The case hotel operates in Taiwan and has 300 employees, all of them being of Taiwanese origin. Data was collected through direct participation in the internal branding project, where the intern researcher could observe the training program, assist in the training program, and scheduled interviews to collect anecdotal testimonies regarding how employees practiced hotel branding and what motivated them to participate at work. The researcher also interviewed employees who previously received awards as well as department managers and worked with the human resource department.

The study's findings suggest that top-level support has a positive influence on the behaviors of front-line employees and that hotel branding can significantly influence cross-department cooperation, employee retention, and performance. These findings suggest that general managersand human resource managers must provide support by incorporating internal branding into practices to secure employees' social identity, which has a positive effect on brand 
performance. Social exchange theory can provide a guideline on how different internal branding strategies can produce different effects within the organization. More specifically, the study highlights the role of social exchange in internal branding by showing the role of corporate support in internal branding when it provides tangible gifts and intangible honors. More so, support from peers appears to increase employees' willingness to show the same type of behaviors.

The study described above supports a different research conducted by Wang, Ryan, and Yang (2019a). In Wang's et al study, data was gathered from hotels located in the United States and Taiwan. Survey questionnaires were sent to hotel managers who then distributed the questionnaires to volunteer employees that complete them anonymously. Responses were also obtained directly by site visits. 207 usable responses were received from seven hotels in the United States and 249 usable responses from eleven hotels in Taiwan. Brand love was measured with ten items revised from Carroll and Ahuvia (2006). The presence of supportive voice behaviors was assessed with five items adapted from Burris (2012). Employee helping behavior was measured with an OCB-I scale from developed by Ma et al., (2013) Organizational culture was evaluated by with scale developed by Cameron and Freeman (1991). Questionnaires were provided in English, Spanish, and Chinese.

Providing a cross-cultural validation, this study showed that brand love can have a positive effect on supportive voice behavior, forgiveness behavior, and helping behavior. More so, hierarchy appeared to increase all of these three types of behaviors, as those who receive help today may become tomorrow's helpers. From the perspective of the social exchange theory, helping behavior is a type of social exchange where peers return resources of services. Supportive voice behaviors are also a social exchange return, where information is a resource. Finally, forgiveness behavior is a social exchange return as it can consist of a return of resources such as money and status.

Organizational culture appears to play the role of moderator, strengthening, and perhaps also weakening employee desired behavior. For instance, hotel employees who love their brand are more likely to show behaviors of commitment at work and, consequently, perform better than other employees. On the other hand, high performers may be punished by peers through subtle means such as withhold of information, withhold of resources, and other forms of sabotage. The rational choice theory predicts that brand lovers may not perform positive behaviors in all contexts if they perceive that the cost of those behaviors is too high. Different organizational settings may influence the likeliness of these types of peer dynamics to occur.

To, Martin, \& Billy (2015) showed that employees' attitudes improve through internal communication. Data was collected from 201 employees of four-star hotels in Macao SAR, China, and interviews were taken by phone or in-person. The researchers used a seven-point Likert scale questionnaire translated from English to Chinese where the employees had to show the extent to which they agree to several statements concerning the management's concern for them, including the subjective perception of management concern and specific actions taken by the management to improve employee experience.

The study found that middle managers have an important role in diffusing the organizational culture to frontline employees, which suggests that they play an important role in internal branding. On the other hand, top managers play a key role in ensuring that middle managers provide support to employees.

Terglav et al., (2016) also assessed the role of brand-oriented leadership of top management as a key driver of internal branding. The study had a sample of 226 employees working in a Slovenian hotel chain. Data was collected on a self-completing questionnaire and included 
employees participating in different operations, including reservation, maintenance, and food waiters and chefs, among other

Brand oriented-leadership was assessed with four items from the brand-oriented transformational leadership scale (Morhart et al., 2009). Psychological contract was measured with two items proposed by Rousseau and Tijoriwala (1998) and one item proposed by Robinson and Rousseau (1994). Employee-brand fit was measured with a three-item scale proposed by Cable and DeRue (2002). Some of the measures were adapted to the brand context.

The study found that employee brand knowledge, brand fit, and psychological contract fulfillment increasing employee brand knowledge and brand fit can increase brand commitment. Top managers appeared to play an important role in internal branding, including in ensuring employees' emotional attachment to the brand.

Chiang (2012) explored the process of internal brand management through the constructs of brand-centered HRM, brand psychological ownership, and brand citizenship behavior. The study was based on data collected from 453 employees, 172 supervisors, and 933 customers from 26 hotels, and a hierarchical learning model was used to assess the relationship between the constructs in question. Data was gathered from a Likert-based questionnaire assessing attitudes and behaviors, including brand organizational citizenship behavior and psychological ownerships. The authors found that brand psychological ownership of employees had a positive effect on brand citizenship behaviors and the factors of both constructs correlated positively. Brandcentered HRM was shown to positively influence brand ownership and citizenship behavior. Finally, brand citizenship behaviors at the organizational level showed a positive relationship with customer satisfaction, and brand ownership was found to mediate the relationship between brand citizenship behavior and brand-centered HRM.

Engagement employees appear to show a higher level of citizenship behavior toward the organization, colleagues, and customers. While employees showing a high level of internal branding may work harder to contribute to the organization's goals, they will not necessarily be more prone to help other individuals in their job tasks unless they have a positive work-related state of mind (Buil, Martínez \& Matute, 2016). In other words, the influence of internal branding on organizational citizenship behavior is explained by the more positive attitudes employees have over their job.

\section{Discussion}

The importance of employees in corporate marketing and branding has become increasingly acknowledged by both researchers and brand owners. Employees interacting directly with customers can have a major influence on customer satisfaction and, consequently, the customers' perception of the brand (Carroll \& Ahuvia, 2006; Terglav et al., 2016). Many brands in the hostelry industry invest time and resources to increase employees' understanding of the brand, yet many fails to acknowledge that brand knowledge by itself does not guarantee positive brand behaviors.

The research works synthesized in the present study suggest that positive brand behaviors are influenced by a constellation of variables that interact with brand knowledge differently. The present literature review proposes that understanding the relationship between internal branding and customer satisfaction, as well as the effects of the variables that mediate the relationship between the same, requires a theoretical framework that explains the psycho-social factors that underly these dynamics. The study evaluated for this paper suggests that the rational choice theory and social exchange theories can provide a specific theoretical interpretation of the effects of internal branding on customer satisfaction.

\section{Communicating the Brand}


It appears that brand training and communication does not have a direct influence on work engagement (Buil, Martinex \& Matute, 2016). From the perspective of the social exchange theory, brand training and communication may only influence work engagement if the work activities create more positive work-related states of mind.

On the other hand, brand training and communication may have an indirect influence on work via organizational identification (Buil, Martínez \& Matute, 2016). Incorporating internal branding into a training program should not only consist of providing brand knowledge but also in providing a sense of brand-related social identity (Wang, Ryan, \& Yang, 2019b).

Using the brand into human resources practices appears to contribute to aligning the values of the organization with the values of those parts of it. This means that hotels promoting brand values within training and communication are more likely to achieve a positive social identity. This relationship may underly a reduction in the gap between the characteristics of the organization and employees' characteristics where employees experience an increased sense of pride in being part of the organization (Punjaisri \& Wilson, 2017).

Wang, Ryan, and Yang (2019a) showed that employees can engage in love-like behaviors towards the brand they represent showing support and forgiveness behaviors. More so, and in consonance with the social exchange theory, hierarchy appears to increase all these three types of behaviors, as those who receive help today may become tomorrow's helpers. When peers provide support, employees are more likely to engage in positive brand behavior (Wang, Ryan, and Yang, 2019b).

When employees gain psychological ownership of the brand, they are more likely to engage in brand citizenship behavior, The HR department can have a positive effect on both brand ownership and citizen behavior. Brand ownership mediates the relationship between brand citizenship behavior and brand-centered HR (Chiang, 2012). This finding is not surprising, as previous studies have found that that employees, even if they have a high level of internal branding, would only be prone to help other individuals in their job task if they have a positive work-related state of mind (Buil, Martínez \& Matute, 2016).

Engaged employees tend to provide better customer services than less engaged ones and employees with a higher level of internal branding are more likely to defend the interests of their organization by making customers happy. The extent to which employees identify with the organization can have an impact on the customers' perception of the brand.

\section{Recognizing Effective Management}

Internal brand management appears to be an effective tool for developing and preserving powerful brands. Internal brand management can be characterized by three elements: brand communication, human resource management, and leadership. Making brand value a component of communication and training can reduce the distance between the employees' and hotel's identity, with transformational leadership being an important antecedent of internal branding and work engagement (Buil, Martínez \& Matute, 2016). These findings suggest that hotels should invest in managers' training and encourage a transformational leadership style.

A branding project should have top-down support from C-level executives and bottom-up support from team unite and player. Following the social exchange theory, resources such as financial incentives and recognition can play a key role in reinforcing internal branding behaviors (Wang, Wang, and Yang, 2019b).

To, Martin and Billy (2015) showed that middle managers have an important role in diffusing the organizational culture to frontline employees while top managers have an important role in ensuring that middle managers provide support to employees as well as providing their own support to employee. In other words, achieving the desired level of internal branding requires the 
active involvement of the management department, with general management and middle managers, such as the HR department, playing specific key roles. A successful implementation of an internal branding strategy requires that each department of the organization understand their role in the program and communicate with other relevant departments.

Communication of brand values and behaviors is very important, as well as determining which employees show a high level of brand-related behaviors. Managers can use several communication approaches, including mentoring, praise, blames, and promoting emotional contagion.

To enable effective internal communication, annual surveys of employees assessing the quality of employment and work attitudes along with staff appraisals can be useful approaches to assess employees' attitudes toward their organization.

\section{Promoting a "Peaceful" Organizational Culture}

The culture of an organization can either strengthen or weaken specific employee behaviors. For instance, some organizational cultures may discourage peer-to-peer aggression. While employees who identify with a brand and who love their brand tend to show positive brand behaviors, the rational choice theory predicts that they may still perform poorly if the perceived cost of being high performers is too high (Campbell et al., 2017). For instance, high performance may be punished by peers.

General management and human resource managers should be aware of the potential negative effect of peer-to-peer aggression on positive brand behaviors and have policies and other types of strategies to reduce the risk of this type of aggression. For example, employees' attitudes towards the brand can be improved through internal communication (To, Martin \& Billy, 2015). More so, when employees have a positive attitude towards their brand, they tend to have a positive workrelated state of mind (Buil, Martínez \& Matute, 2016) and are more likely to help other individuals in their job tasks.

\section{Limitations and Future Research}

The studies included in the present literature review have been conducted in several countries with different groups of people. For this reason, it can be assumed that the results are generalizable to organizations from all over the world, at least those that belong to the hospitality industry. On the other hand, some studies had small samples, homogenous demographic groups, and all expect one has a cross-sectional design.

The lack of longitudinal studies to include may be the most important limitation of this review. It would be interesting to see how different internal branding strategies produce different effects on brand-related behaviors. More specifically, future longitudinal studies could explore the effects of different internal branding strategies on psychological brand ownership, peer reactions to high performance, work engagement, and any other variables that may influence positive brand behaviors and, consequently, customer satisfaction.

\section{Conclusion}

As shown, the rational choice theory and social exchange theory can be used to explain employee behavior in relation to internal branding. The rational choice theory understands employee behaviors in terms of utility maximization, which explains while brand knowledge and even positive attitudes toward the brand cannot fully account for positive brand behavior. The social exchange theory, on the other hand, considers that employees become committed to a brand when they receive an exchange of benefits, an assumption which is supported by several studies in internal branding. The findings of the present literature review suggest that internal branding can significantly influence employee engagement and, consequently, customer satisfaction. The 
studies included for the review suggest that positive brand behaviors are predicted by psychological brand ownership, an organizational culture that discourages peer aggression, and an effective use of both tangible and intangible incentives.

\section{References}

Burris, E. R. (2012). The Risks and Rewards of Speaking up: Managerial Responses to Employee Voice. Academy of Management Journal, 55(4), 851-875.

Burmann, C., \& Zeplin, S. (2005). Building Brand Commitment: a Behavioural Approach to Internal Brand Management. Journal of brand management, 12(4), 279-300.

Cable, D. M., \& De Rue, D. S. (2002). The Convergent and Discriminant Validity of Subjective Fit Perceptions. Journal of applied psychology, 87(5), 875-844.

Campbell, J. P., \& Freeman, S. J. (1991). Cultural Congruence, Strength and Type: Relationships to Effectiveness, İçinde Woodman, RW and Passmore, WA (Der.). Research in Organizational Change and Development. Greenwich.

Campbell, E. M., Liao, H., Chuang, A., Zhou, J., \& Dong, Y. (2017). Hot Shots and Cool Reception? An expanded view of social consequences for high performers. Journal of Applied Psychology, 102(5), 845-866.

Carroll, B. A., \& Ahuvia, A. C. (2006). Some antecedents and outcomes of brand love. Marketing letters, 17(2), 79-89.

Keller, K. L., Parameswaran, M. G., \& Jacob, I. (2011). Strategic Brand Management: Building, Measuring, and Managing Brand Equity. Pearson Education India.

Ma, E., Qu, H., Wilson, M., \& Eastman, K. (2013). Modeling OCB for Hotels: Don't Forget the Customers. Cornell Hospitality Quarterly, 54(3), 308-317.

Martínez, E., \& Matute, J. (2016). From Internal Brand Management to Organizational Citizenship Behaviours: Evidence from Frontline Employees in The Hotel Industry. Tourism Management, 57, 256-271.

Melewar, T. C., Gotsi, M., Andriopoulos, C., Chang, A., Chiang, H. H., \& Han, T. S. (2012). A Multilevel Investigation of Relationships Among Brand-Centered HRM, Brand Psychological Ownership, Brand Citizenship Behaviors, and Customer Satisfaction. European Journal of marketing, 46(5), 626-662.

Morhart, F. M., Herzog, W., \& Tomczak, T. (2009). Brand-specific leadership: Turning Employees into Brand Champions. Journal of Marketing, 73(5), 122-142.

Mosley, R.W. (2007). Customer Experience, Organisational Culture and the Employer Brand Journal of Brand Management, 15 (2), 123-34

Organ, D. W. (2018). Organizational Citizenship Behavior: Recent Trends and Developments. Annual Review of Organizational Psychology and Organizational Behavior, 80, 295-306.

Punjaisri, K., Evanschitzky, H., \& Wilson, A. (2009). Internal Branding: an Enabler of Employees' Brand-Supporting Behaviours. Journal of Service Management, 20(2), 209-226.

Punjaisri, K., \& Wilson, A. (2011). Internal Branding Process: Key Mechanisms, Outcomes and Moderating Factors. European Journal of Marketing, 45(9-10), 1521-1537.

Punjaisri K \& Wilson A., (2017). The Role of Internal Branding in the Delivery of Employee Brand Promise. In: Balmer J.M.T., Powell S.M., Kernstock J., Brexendorf T.O. (eds) Advances in Corporate Branding. Journal of Brand Management: Advanced Collections. Palgrave Macmillan, London, 91-108.

Robinson, S. L., \& Rousseau, D. M. (1994). Violating the Psychological Contract: Not the exception But the Norm. Journal of organizational behavior, 15(3), 245-259. 
Rousseau, D. M., \& Tijoriwala, S. A. (1998). Assessing Psychological Contracts: Issues, Alternatives and Measures. The International Journal of Industrial, Occupational and Organizational Psychology and Behavior, 19(1), 679-695.

Rousseau, D. M., \& Shperling, Z. (2003). Pieces of the Action: Ownership and the Changing Employment Relationship. Academy of Management Review, 28(4), 553-570.

Terglav, K., Ruzzier, M. K., \& Kaše, R. (2016). Internal Branding Process: Exploring the Role of Mediators in Top Management's Leadership-Commitment Relationship. International Journal of Hospitality Management, 54, 1-11.

To, W. M., Martin Jr, E. F., \& Billy, T. W. (2015). Effect of Management Commitment to Internal Marketing on Employee Work Attitude. International Journal of Hospitality Management, 45, 14-21.

Van Dyne, L., \& Pierce, J. L. (2004). Psychological ownership and Feelings of Possession: Three Field Studies Predicting Employee Attitudes and Organizational Citizenship Behavior. The International Journal of Industrial, Occupational and Organizational Psychology and Behavior, 25(4), 439-459.

Wang, Y.-C., Ryan, B., \& Yang, C.-E. (2019a). Employee Brand Love and Love Behaviors: Perspectives of Social Exchange and Rational Choice. International Journal of Hospitality Management, 77, 458-467.

Wang, Y.-C., Yang, J., \& Yang, C.-E. (2019b). Hotel Internal Branding: A participatory Action Study with a Case Hotel. Journal of Hospitality and Tourism Management, 40, 31-39.

Xiong, L., King, C., \& Piehler, R. (2013). That's not My Job: Exploring the Employee Perspective in the Development of Brand Ambassadors. International Journal of Hospitality Management, 35, 348-359.

Xiong, L., \& King, C. (2019). Aligning Employees' Attitudes and Behavior with Hospitality Brands: The Role of Employee Brand Internalization. Journal of Hospitality and Tourism Management, 40, 67-76. 